\title{
Surgical repair of subaortic stenosis in atrioventricular canal defects
}

\author{
A 6-month-old male infant with partial atrioventricular canal defect and subaortic stenosis had a \\ mitral valve releasing procedure to correct the subaortic stenosis with concomitant repair of the canal \\ defect. An echocardiogram done 1 year after the operation shows no subaortic gradient and no mitral \\ regurgitation. We present the details of the surgical technique and the common pitfalls in recognizing \\ and treating this entity. (J Thorac Cardovasc Surg 1994;108:373-6)
}

Albert Starr, MD, and Hagop Hovaguimian, MD, Portland, Ore.

\begin{abstract}
$\mathrm{S}$ Subaortic stenosis is a relatively uncommon finding in atrioventricular (AV) canal defects, with a reported prevalence of $3 \%$ to $7 \% .^{1-4}$ It continues to pose a serious challenge to both preoperative diagnosis and successful surgical repair. Numerous reports have discussed the different underlying causes and have suggested surgical strategies to avoid this complication during the primary repair of the defect..$^{5-7}$

This report describes the successful repair of a partial AV canal defect with an existing subaortic gradient. Although a similar technique has been described previously, the results have been unfavorable and may have caused the relative unpopularity of this technique.
\end{abstract}

\section{Case history}

A 6-month-old male infant had a diagnosis of partial AV canal defect, mild mitral regurgitation, mild subaortic stenosis, and Noonan's syndrome. His main symptom was failure to thrive. The echocardiogram demonstrated a long left ventricular outflow tract and low attachment of the mitral valve. Cardiac catheterization revealed a left ventricle-aorta gradient of $30 \mathrm{~mm} \mathrm{Hg}$ and a pulmonary/systemic flow ratio of $3: 1$.

Through a standard median sternotomy, cardiopulmonary bypass was instituted with bicaval and ascending aortic cannu-

From the Albert Starr Academic Center for Cardiac Surgery, St. Vincent Hospital and Medical Center; Portland, Ore. Surgery performed at Emanuel Hospital Children's Cardiac Center, Portland, Ore.

Received for publication Dec. 8, 1993.

Accepted for publication Jan. 9, 1994.

Address for reprints: Albert Starr, MD, The Albert Starr Academic Center for Cardiac Surgery, 9155 S.W. Barnes Rd., Suite 240; Portland, OR 97225.

Copyright $\odot 1994$ by Mosby-Year Book, Inc.

$0022-5223 / 94 \$ 3.00+0 \quad \mathbf{1 2 / 1 / 5 4 6 1 1}$ lation. The infant was cooled to $22^{\circ} \mathrm{C}$, and cardiac arrest was achieved by cold hyperkalemic blood cardioplegia. Through an aortotomy and right atriotomy, the subaortic area was interrogated. The upper crest of the interventricular septum where the mitral and tricuspid valve components were attached was found to have a significant concavity toward the apex of the heart. This malformation had resulted in the anterior half of the cleft mitral leaflet crowding the already narrow subaortic space and causing subaortic stenosis. This leaflet was detached from the crest of the interventricular septum, the tricuspid component being left intact. A triangular patch of glutaraldehyde-treated autologous pericardium was sutured to the septum. The freed margin of the anterior mitral leaflet was then reattached to the patch with 6-0 Dacron horizontal mattress sutures (Fig. 1). A second patch of glutaraldehyde-treated pericardium was used to close the ostium primum after the mitral valve cleft had been closed as per our routine. The aortotomy and atriotomy were then closed. The infant was weaned off cardiopulmonary bypass without difficulty, receiving no pressors. Postoperative echocardiograms showed a wide left ventricular outflow tract, no left ventricle-aorta gradient, and no mitral regurgitation. The infant was discharged home on the seventh postoperative day. On follow-up echocardiogram after 1 year, no left ventricleaorta gradient or mitral regurgitation was apparent.

\section{Discussion}

An excellent study by Blieden and associates ${ }^{8}$ compared dimensions of the left ventricle in normal hearts and hearts with partial AV canal defect. The length between the mitral valve and apex and that between the apex and aortic valve were measured and termed the "inflow" and "outflow" dimensions, respectively. Ratios of these lengths were found to be $1: 1$ in normal hearts and as little as 0.7:1 in hearts with AV canal defect. The reduced inflow length alters ventricular geometry and results in a narrower left ventricular outflow tract. This underlying abnormality makes the left ventricular outflow tract more vulnerable to stenosis (Fig. 2).

Although the primary feature of a partial AV canal 


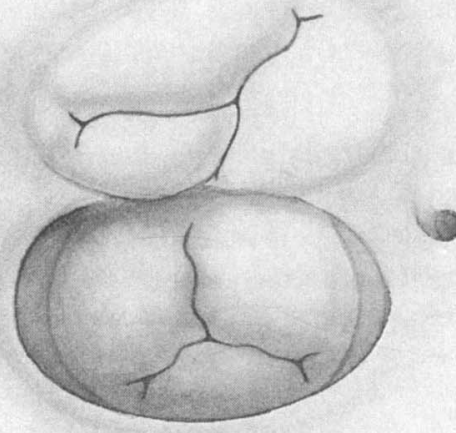

a

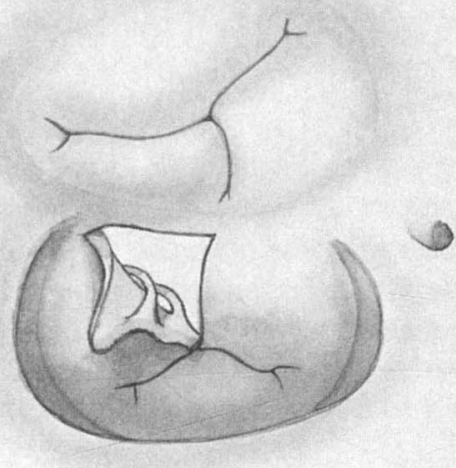

b
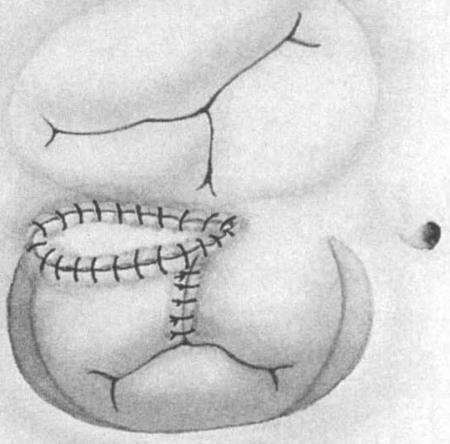

C

Fig. 1. a, Right atrial approach to the tricuspid and mitral valves. b, Anterior leaflet is detached from the septal crest to interpose a small patch that will allow reattachment of the leaflet at a higher level. c, The patch partially fills the scooped-out defect in the septum. After resuspension of the leaflet, the mitral cleft was sutured and the primum defect was closed in the usual fashion.

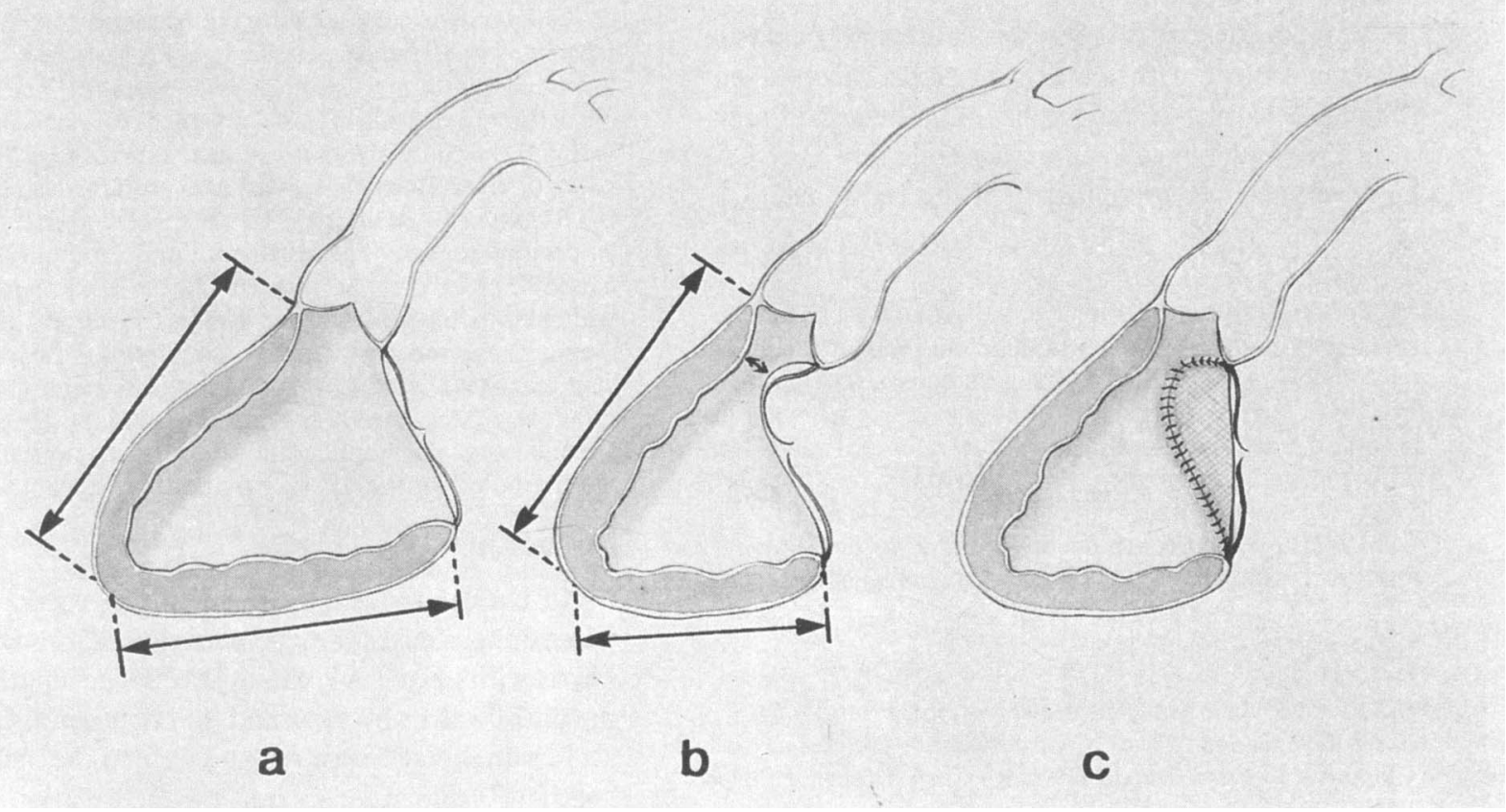

Fig. 2. a, Long-axis section through the normal left ventricle. Note that inflow and outflow lengths are approximately equal. $\mathbf{b}$, The underlying morphologic anomaly that results in the "goose-neck" appearance of the left ventricle. Note that the left ventricular inflow/outflow ratio is significantly reduced. The asymmetric contour of the scooped-out area of the interventricular septum is characteristic, and the anterior mitral leaflet's close attachment to this deficient septum contributes to the narrowing, which results in subaortic stenosis. c, After repair, the same abnormal geometry persists, but the outflow tract has been restored to normal dimensions by lifting the mitral leaflet to the natural level. 


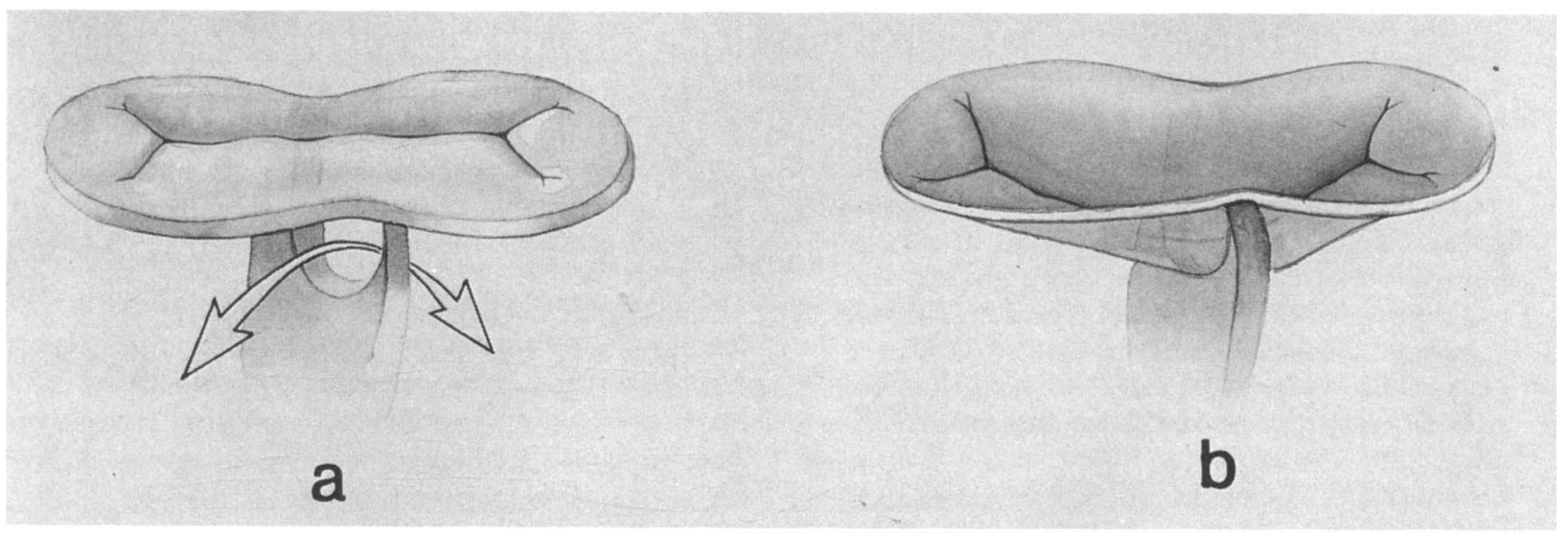

Fig. 3. A stylized view of the relationship of the AV valves to the interventricular septum. a, Complete AV canal defect. b, Partial AV canal defect. Note the concavity created in the anterior leaflet of the valve. The valve releasing prodedure described in this paper would convert $\mathbf{b}$ to $\mathbf{a}$ and close the created defect with a patch.

defect is the absence of a ventricular septal defect, morphologically some degree of concavity of the superior margin of the interventricular septum is frequently present, with the mitral and tricuspid components of the AV valves attached to it. When this "scooped-out" portion of the interventricular septum is deep, the mitral valve, following the concavity of the interventricular septum, encroaches on the subaortic area, which is already narrower than usual, resulting in substantial subaortic stenosis (Fig. 3).

A similar situation can be created in hearts with Rastelli type A AV canal defect when the ventricular septal defect is deep and the chordae attaching the valves to the septal crest are short.

Occasionally a fibrous ridge is found in the subaortic region along with a thickened mitral subvalvular apparatus, probably the result of turbulent flow, which may compound or "create" left ventricular outflow tract obstruction. $3,4,9$

This anomaly can be repaired by essentially converting the partial canal defect to a complete defect at the anterior portion and by eliminating the concavity of the interventricular septum by adding a subvalvular patch of pericardium or Dacron fabric. This patch will lift the anterior segment of the mitral leaflet and enlarge the subaortic space. The same should be done in the case of type A complete canal with short chordae (as mentioned earlier) by dividing the chordae attaching the mitral leaflet to the septal crest and reattaching it at a higher plane, toward the atrium.

Although this technique of repair was described by Lappen and associates ${ }^{6}$ in 1983 and by DeLeon and colleagues $^{1}$ in 1991 , neither of the authors recommended liberal use of the procedure because of their unfavorable outcomes. The excellent outcome for our patient with neither mitral regurgitation nor subaortic gradient after the operation encourages us to recommend this procedure.

We also recommend a very high index of suspicion of subaortic stenosis when evaluating patients with partial or Rastelli type A complete AV canal defect, because of the insidious nature of subaortic stenosis in these cases. $5,7,10$ The significance of a "mild" gradient in the preoperative evaluation of these children may be wrongly dismissed because it is considered an inherent feature associated with the "goose-neck" deformity. In addition, this stenosis is frequently underestimated because of the low systemic cardiac output and high left-to-right shunt, which results in a low gradient. Increasing dependence on echocardiography alone, without catheterization, will make us even more vulnerable to these pitfalls and may explain why subaortic stenosis sometimes tends to appear de novo after primary repair of these defects. Once subaortic stenosis is suspected, careful intraoperative evaluation of the interventricular septal crest, the attached mitral valve, and the subaortic area must be carried out, with liberal indications for undertaking a mitral valve releasing procedure. It is to be hoped that this aggressive approach may prevent future operations for subaortic stenosis, which are known to be significantly more difficult. The excision alone of fibrous hyperplasia or an incomplete ring, when present in the subaortic area, may not be adequate and may result in recurrence over time., ${ }^{3,9}$

We gratefully acknowledge the clinical assistance and insight of the pediatric cardiologist, Dr. Douglas King. Acknowledgement is also due the medical illustrator, Joanie Livermore, and 
Dr. Hemant Trehan for their assistance with the manuscript and illustrations.

\section{REFERENCES}

1. DeLeon SY, Ilbawi MN, Wilson WR, et al. Surgical options in subaortic stenosis associated with endocardial cushion defects. Ann Thorac Surg 1991;52:1076-83.

2. Somerville J. Atrioventricular defects: natural and unnatural history. In: Godman M, ed. Paediatric cardiology. Edinburgh: Churchill Livingstone, 1980.

3. Ceithaml EL, Midgley FM, Perry LW. Long-term results after surgical repair of incomplete endocardial cushion defects. Ann Thorac Surg 1989;48:413-6.

4. Braunwald NS, Morrow AG. Incomplete persistent atrioventricular canal. J THORAC CARDIOvASC SURG 1966; 51:71-80.

5. Ebels J, Meijboom EJ, Anderson RH, et al. Anatomic and functional "obstruction" of the outflow tract in atrioventricular septal defects with separate valve orifices ("ostium primum atrial septal defect"): an echocardiographic study. Am J Cardiol 1984;54:843-7.

6. Lappen RS, Muster AJ, Idriss FS, et al. Masked subaortic stenosis in ostium primum atrial septal defect: recognition and treatment. Am J Cardiol 1983;52:336-40.

7. Taylor NC, Somerville J. Fixed subaortic stenosis after repair of ostium primum defects. Br Heart J 1981;45:68997.

8. Blieden LC, Randall PA, Castaneda AR, Lucas RV, Edwards JE. The "goose neck" of the endocardial cushion defect: anatomic basis. Chest 1974;65:13-7.

9. Heydarian M, Griffith BP, Zuberbuhler JR. Partial atrioventricular canal associated with discrete subaortic stenosis. Am Heart J 1985;109:915-7.

10. Ben-Shachar G, Moller JH, Castaneda-Zuniga W, Edwards JE. Signs of membranous subaortic stenosis appearing after correction of persistent common atrioventricular canal. Am J Cardiol 1981;48:340-4. 